\title{
International overview of high-level simulation education initiatives in relation to critical care
}

\begin{abstract}
The use of simulation in healthcare education has become very topical across all professions and specialties in order to improve patient safety and quality of care. In the last decade, the adoption of more realistic simulation-based teaching methodologies, which serves as a bridge between the acquisition and application of clinical skills, knowledge, and attributes, has been accompanied by the development of a multitude of international and national simulation societies. These serve as important exchange fora for educators, clinicians, researchers, and engineers who desire to learn and share their experience and knowledge around simulation-based education. Several countries have derived their own strategy in order to promote the use of such training methodology. Current key national strategies will be presented in this paper alongside a discussion of their expected impact. Various approaches have been adopted and each has their own place and the potential to be adopted by other nations depending on their political, economic, or even geographic context. Within the critical care arena, simulation has generated considerable interest and there is a growing evidence base for its use as a learning and teaching strategy within this environment. A number of critical care related associations and societies are now recognising simulation as an appropriate pedagogical approach and acknowledging its potential to improve patient care and clinical outcomes. Its implementation should be carefully considered to ensure that developments are based on current best educational practice to maximise the efficiency of these educational interventions.
\end{abstract}

\section{International overview of high-level simulation education initiatives in relation to critical care}

\section{Aims and Objectives}

The aim of this paper is to bring to the attention of the readership the emerging prevalence around the world of the adoption of simulation-based educational approaches, sometimes combined with technology, that have for objective to improve patient safety and the quality of care at a national level. Whilst highlighting a number of important national initiatives, this introductory paper will also briefly discuss a few historical milestones which have shaped simulation education developments and the current simulation methodologies used for educational and assessment purposes.

The key message of this paper is that the national initiatives presented have in common the objective to shape or at least inform the future of initial or pre-registration training and ongoing professional development of the healthcare workforce of the various concerned countries. These initiatives, whether they are in the form of an official and national report, legislation, or project, are highly relevant to other nations around the globe due to their potential transferability of the approaches adopted and the importance of the message they carry; a better trained healthcare workforce would unquestionably improve patient safety and patient outcome. This applies to all healthcare environments. 


\section{Background}

In the clinical education context and inspired by the published taxonomy of the 2007 Simulation Education Summit (Huang et al., 2008), "simulation" can be defined as being a technique that recreates a situation or environment to allow learners (in the widest sense of the term) to experience an event or situation for the purpose of assimilating knowledge, developing or acquiring cognitive and psychomotor skills, practising, testing, or to gain understanding of systems or human actions and behaviours. Simulation is a "process" which is not to be confused with the "tool" or "means", called the "simulator" (whether it is a model, part-task trainer, mannequin, computer software, or a simulated patient), used to achieve the intended learning outcomes or for evaluation or assessment purposes of cognitive, behavioural or/and psychomotor skills, and clinical competencies. Early records of the use of simulation for educational purposes date back to the eighteenth century and the pioneering work of a midwife commissioned by the King of France, Louis $\mathrm{XV}^{\text {th }}$, to conduct an educational campaign in rural areas of France (Gelbart, 1998). Madame du Coudray developed the model of a female pelvis with a uterus that she used as a part-task trainer with an accompanying illustrated training manual translated in different languages to demonstrate the safe delivery process of singletons and twins (p.62). It is reported that over 23 years she trained an estimated 10,000 peasant women as birthing assistants (p.277), teaching them how to safely deliver babies and perform manoeuvres for managing childbirth-related complications.

A century later another important model was made in Norway, the Laerdal Resusci-Ann mannequin torso, to help practise other life saving skills such as mouth-to-mouth, then cardiopulmonary resuscitation (Lind, 1961). In parallel the first full-scale patient simulator, SimOne, was being developed in the USA (Abrahamson et al., 1969) but only to be ever used by a few privileged trainees. It is not until the 1990's that similar work culminated with the successful commercialisation of full-body simulators (Rosen, 2008). Due to the price of these sophisticated interactive training models operating from complex mathematical models of physiology and pharmacology, called high-fidelity patient simulators, their adoption has been somewhat slow but has now greatly improved thanks to the development of more affordable versions primarily relying on an operator to modify "on the fly" or pre-programme the physiological parameters according to the treatment provided by trainees and the desired patient case to be simulated. Such mannequins are commonly referred to as intermediate or mid-fidelity patient simulators (Alinier, 2007).

All the above developments, as well as a few others not reported in this paper such as the long standing and widely adopted Harvey cardiologic patient simulator (Issenberg, 2006a), happened mostly in isolation from government initiatives, but were guided by teams of individuals with a clear determination and vision to improve clinical training. Without all these early developments, the opportunities offered today by the adoption of simulation-based education may not yet be available to educational and healthcare institutions. 


\section{Simulation in the twenty first century}

The use of simulation in healthcare education has dramatically evolved and broadened in terms of applications and educational value recognition since the turn of the century. The term "dramatically" can be taken literally as to address specific learning objectives, facilitators are sometimes required to participate in scenarios and play specific roles to observe the learners' responses or actions to events they purposefully trigger or situations they create. There is increasing recognition that less emphasis should be placed on the tool, but that we should instead pay more attention to the way we educate our learners using simulation as a technique and the resources already available in one's institution. In effect, the emphasis has shifted to the overall simulation education programmes and their facilitators to ensure the programmes are educationally sound, appropriately supported, and that the persons supporting, delivering or facilitating it have grasped and used the correct educational techniques and approaches or may even have appropriate credentials to do so. A paper by Lambton and Prion (2009) highlights the fact that the "faculty" need to possess: educational, clinical and technical expertise. Commonly called "Train-the-Trainer" courses have been developed and run by a number of centres that were early adopters of the more realistic or "high-fidelity" simulation-based educational approach (Issenberg, 2006b), whilst not being formally accredited or endorsed by any learned society at the time. Such courses are not a perfect solution as they end up being either too generalist or too focused, whilst fellowship or mentorship programmes allow people to acquire enough experience to help start other simulation programmes (Carney, 2007). The importance of preparation and skills mix among the team facilitating a simulation session is now more widely recognised. The wide array of skills required of the ideal simulation educator on a simultaneous basis can be overwhelming for anyone to perform over time on an individual basis. In real terms this actually ends up being a team effort as finding all the required attributes (clinical, educational, and technical expertise and interest) in a single person is very difficult. It is increasingly acknowledged that we should strive to maximise the students' learning and make the best use of the resources (Leigh and Hurst, 2008) and for this each institution should strive to have "a champion for simulated technology use, a faculty member who believes in the technology, is informed and excited about its use, and has a "contagious" effect on other faculty members." (p.34) (Medley and Horne, 2005). From this point onwards a team can be formed and complemented as and when required by other members bringing their own knowledge and skills to the simulation programmes.

\section{Simulation-based education as a new specialty}

The formalisation of simulation-based educational practices has really progressed thanks to the development of international and national multidisciplinary societies, usually aimed at a broad membership of healthcare educators, clinicians, researchers and engineers, and supported by industry. These societies sometimes focus on specific specialties such as paediatrics or nursing for example, but all share a common interest for simulated clinical practice and have associated meetings and conferences which serve as key exchange fora around the implementation of simulation-based initiatives and educational or patient outcome-based research. The first such clinical simulation society 
was officially set up in Europe in 1993 by a small group of people under the name of the Society in Europe for Simulation Applied to Medicine (SESAM, www.sesam-web.org) with an associated scientific meeting that moved from being biannual to annual in 1998 (Rosen, 2008) and a membership that gradually increased to nearly 500 dedicated professionals from about 40 countries. In the USA, the Society for Simulation in Healthcare (SSH, ssih.org) was officially created in 2004 with its annual meetings that now attracts well over 3,500 delegates representing all continents. SSH is recognised as the international simulation society, publishes its own peer reviewed journal (Simulation in Healthcare) with a distinguished editorial board since 2006, and acts as a central hub for all clinical simulation societies worldwide through affiliation agreements. It is a very active society working on a number of key initiatives including accreditation of simulation programmes and certification of simulation educators (SSH - Society for Simulation in Healthcare, 2013). Other important societies are the International Nursing Association for Clinical Simulation and Learning (INACSL, www.inacsl.org) which was created in 2001 and also publishes its peer reviewed journal (Clinical Simulation in Nursing), and the International Pediatric Simulation Society (IPSS, www.ipedsim.com) with its annual conference. A particularly relevant society with its UK-based annual meeting is the Association for Simulated Practice in Healthcare (ASPIH, www.aspih.org.uk) which was formed in 2009 following the merger of the National Association of Medical Simulators (NAMS) with the Clinical Skills Network (CSN). It has for overarching goal to enable wider sharing of knowledge, expertise, and educational innovation related to simulated practice across the healthcare professions.

In the UK professional governing bodies such as the Nursing and Midwifery Council (NMC) are now recognising the place of simulation in the preparation of undergraduate nursing students for practice. The three-year university-based programme comprises of 4,600 hours divided equally between theoretical study and clinical training; 50 percent theory (2,300 hours) and 50 percent practice $(2,300$ hours). In relation to the latter the NMC identified that up to 300 hours of the practice hours could be undertaken as simulation to prepare students for practice (Nursing and Midwifery Council, 2007). This clearly demonstrates the NMC's confidence in the educational value of the experience acquired by students in a simulated context.

\section{National initiatives promoting innovative teaching approaches}

ASPiH and several of its members have had a significant input in the production of a report addressed to commissioners and providers of health and social care education that was published end of 2011 by the Department of Health (2011). Its focus was to present a framework providing guidance to help deliver high quality, cost effective education, training and continuous development to the healthcare workforce through the use of technology. This "Framework for Technology Enhanced Learning" identifies six key principles regarding the use of technology as part of a learning solution (Department of Health, 2011). These principles have been derived for the benefit of patients to ensure that the education provided to the healthcare workforce improves patient outcomes, safety, and experience. The recommendations of the framework are that Technology Enhanced Learning should: 
- be patient centred and service driven

- be educationally coherent

- be innovative and evidence based

- deliver high quality educational outcomes

- deliver value for money

- ensure equity of access and quality of provision.

The framework, in line with the White Paper 'From equity to excellence: Liberating the NHS' (Department of Health, 2010), recognises the value of local ownership and diversity, and highlights the benefits of appropriate co-operation and collaboration where this can deliver more cost effective solutions than fragmented local provision. In many instances it means making effective use of existing resources and know-how rather than duplicating resources and efforts related to course developments and delivery. Such initiatives have already been put in place in other places (Waxman et al., 2011). Quite often, as opposed to purchasing new equipment, starting a simulation programme may simply involve adapting the way current resources and equipment are being used by clinical educators. Although people are inclined to purchase new equipment to renew the enthusiasm, it is very common all over the world for new training equipment to be purchased and remain in the box for several months and even years before it is used. Educators often remain accustomed to their usual way of providing training and "do not have the time" to learn about different teaching approaches and to understand how to use new pieces of equipment that may be more sophisticated and might be more complex to use. The push for innovation and evidence based is a particularly pertinent prompt for educators to review their current practice as what we have been doing for a long time is not necessarily the best way of doing it.

An interesting example is the work done at Imperial College on what they call "Distributed Simulation" (DS) which they frame as a "disruptive innovation" and demonstrating that a fixed and expensive training facility is not always necessary and that immersive simulation can be achieved in a limited space and with limited resources (Kneebone et al., 2010). They have had the idea of creating a portable simulation training environment made of an inflatable enclosure, pop up banners to represent the clinical context and medical devices, audio effects of the clinical environment, a simple audio-visual recording system concealed into the lighting equipment, and a central stage where the attention of the learners is focused whilst they take part in a full scale scenario by either treating a patient simulator, an actor, or a part-task or surgical trainer, and interacting with the rest of the clinical team. The successful implementation of this approach demonstrates that high-fidelity immersive simulation can be achieved by concentrating on the high-fidelity aspects of the key learning elements on which the learners are focusing whilst simply providing a visual representation of more peripheral elements. For example, in the DS environment recreated the walls and large pieces of medical equipment are fake (i.e. inflatable wall and pop-up banners as visual cues for the medical equipment), however the open abdominal wound on which the surgical team is concentrating is highly realistic in terms of appearance and texture.

Other countries such as Australia and France have also given serious considerations in terms of making recommendations regarding the adoption of the latest training approaches for the initial and ongoing education of healthcare professionals with a particular emphasis on simulation (Granry and Moll, 2012, HWA - Health Workforce Australia, 2009, HAS - Haute Autorité de Santé, 2012). In the United States a 
coalition called AIMS (Advancement in Medical Simulation) was created in 2004 to put forward a legislation promoting innovative training approaches. In 2009, a medical simulation bill was introduced in the senate but is yet to gain more supporters among the politicians to make it a legislation (AIMS Advancement In Medical Simulation, 2009). This American legislation would aim to extend the benefits of advanced medical simulation technology to the civilian healthcare system through the deployment of simulation technologies and the incorporation of such technologies and equipment into the education and training protocols of all healthcare professionals. In Australia, the interest in seeing an increased and consistent use of simulated learning modalities to develop clinical skills and competencies across all healthcare professions has been centrally supported as a fully funded governmental initiative since early 2011 and covers capital establishment costs, recurrent funding, and the training of simulation educators and technicians. As eluded in the Framework for Technology Enhanced Learning report (Department of Health, 2011), this Australian government initiative also encourages educational coherence and has actually put in place a national training programme for both the simulation educators and technicians (AusSETT - Australian Simulation Educator and Technician/coordinator Training program, 2012). It is a visionary action from the Australian government with an expected medium term return on investment through enhanced healthcare workforce capacity building, expected improved patient care which is also linked to reduced patient care cost as demonstrated in a study by Cohen et al. (2010). In the UK, a collaborative project started in 2012 between the Higher Education Academy (HEA) and ASPiH to create and support a dedicated national network of Simulation Development Officers (SDO's) (HEA and ASPiH, 2012). This initiative has been created in support of the DH Framework for Technology Enhanced Learning (2011) through the development of a community of educators and practitioners involved with the development and enhancement of simulation-based learning and teaching across all health and social care professions. It aims at establishing much closer links at a local, regional, and national level concerning the use of simulation-based education between organizations involved with the development of a safe and capable health care workforce (HEA and ASPiH, 2012).

\section{Simulation in Critical Care}

Within the critical care arena, simulation as a learning and teaching strategy has generated considerable interest as it is well suited to this environment (Lam et al., 2010). Lam et al. (2010) argue that despite the lack of proven impact on patient outcomes it will continue to play a prominent role in critical care education in the future. This can be seen by the number of critical care related associations and societies acknowledging simulation as an appropriate pedagogical approach. In the UK, the Intensive Care Society (ICS - www.ics.ac.uk), The Faculty of Intensive Care Medicine (FICM - www.ficm.ac.uk), and The Royal College of Anaesthetists (RCoA - www.rcoa.ac.uk) have developed steering groups to explore the use of simulation. Recently the British Association for Critical Care Nurses (BACCN) had simulation as a major theme at their 4th International conference held September 2012.

In Europe, simulation is included as a learning and teaching methodology in the COmpetency-BAsed TRaining in Intensive Care medicine - Information Transfer project (COBATRICE-IT - 
www.cobatrice.org/en/index.asp), which is endorsed by the European Society for Intensive Care Medicine (ESICM - www.esicm.org).

Within critical care it has been suggested by a number of authors (Doyle, 2002, Lam et al., 2010, ICS Intensive Care Society, 2012) that simulation can be used for the following activities:

Teaching, training and workforce development

Technical skills training (E.g. Insertion of vascular catheters)

Interactive physiological modelling.

Point of care simulation (Addressing local needs)

Non-technical skills (E.g. communication skills)

Competency-based assessment

Human performance

Recruitment

Performance feedback

Critical incidents

Deliberate practice of common and uncommon scenarios

Doctors in difficulty

Revalidation

Multidisciplinary team working particularly crisis resource management

Assessment of team performance

Human factors

Although the effectiveness of simulation-based education in nurses' continuing education is still largely unknown (Jansson et al., in press), within medical education following a systematic review McGaghie et al (2010) felt that there is no doubt that simulation technology can produce substantial educational benefits. In relation to critical care a number of studies (Burden et al., 2012, Buykx et al., 2011, Calhoun et al., 2011, Cohen et al., 2010, Mah et al., 2009, Schmitz et al., 2008, Smith et al., 2010, Clapper, 2012, Kim et al., 2009) highlight the potential of this teaching methodology especially in the context of the recommendations outlined in the Technology Enhanced Learning Framework (Department of Health, 2011). 


\section{Impact of simulation initiatives on Critical Care and patient safety}

The challenge for critical care is to collaborate with the various simulation associations and societies to ensure that simulation is delivered in an appropriate manner which implies adhering to the standards of best practice that are being developed. For example the International Nursing Association for Clinical Simulation and Learning identified a number of standards for the delivery of effective simulation (INACSL - International Nursing Association for Clinical Simulation and Learning, 2011), the Society for Simulation in Healthcare has also published its accreditation standards for simulation programmes (SSH - Society for Simulation in Healthcare, 2012), and in the UK, a new framework presented by the Department of Health (2011) also needs to be considered.

As previously identified, central to this is the patient, and safe and effective practice. So what effect can it have on patient safety within critical care? At a psychomotor level a number of studies and evaluations have been undertaken looking at the efficacy of simulation in developing skills in the management of central lines (Cohen et al., 2010, Smith et al., 2010, Burden et al., 2012, Clapper, 2012). Using a blended learning approach, Burden et al (2012) demonstrated that including a mandatory simulation-based training programme resulted in a significant reduction in the incidence of catheter related infections $(P<0.05)$. Although there was not a significant difference in patient mortality, they found a $47 \%$ reduction in costs which they attributed to shorter ICU and hospital lengths of stay. This reduction in cost was also found by Cohen et al (2010) who concluded that a simulation-based educational intervention for central line insertion was highly cost-effective, and suggested that the investment in simulation training can produce significant medical care cost savings.

Following the introduction of a central line insertion simulation course aimed at improving procedural performance, Smith et al (2010) demonstrated a significant improvement in participants' skills immediately after simulation training. However, following the delayed post-testing of participants in the intervention group, their performance diminished and was not significantly different from those in the control group. Interestingly in terms of the use of simulation as a learning and teaching methodology they suggested that it accelerated the learning of the intervention group participants, which in terms of patient safety could potentially reduce the risk to patients. As Kneebone et al. (2004) identified, it is no longer acceptable for novices to gain their basic skills on real patients due to the risks of errors occurring. Smith et al (2010) further suggested that key to expert performance was the use of sustained, deliberate practice. There are several key concepts related to this approach as it is not just about how much an individual practices but how they actually undertake this practice (Ericsson, 2004). They need well defined goals, immediate feedback on performance and then be provided with further opportunities to repeat the simulation to refine their performance (Ericsson, 2008, Ericsson et al., 1993, McGaghie et al., 2010). Abe et al (2013) also found that repeating simulation scenarios improved not only the nurses' technical skill but also their non-technical skills. Continuing on the patient safety theme Ford et al (2010) compared the rate of medication administration errors by critical care nurses following the introduction of mannequin-based simulation training compared to traditional didactic lecture. Their findings showed that the introduction of their simulation-based training programme reduced the number of medication administration errors compared to the nurses who received only the lecture style education. 
Simulation allows teams to practise safely, reducing the risk to patients (DH 2011), and as the ICS (2012) suggests, simulation as an educational methodology is very well suited to the acquisition of nontechnical skills within critical care. In a study on the compliance by multi-professional teams to the guidelines for the management of sepsis, Mah et al (2009) found that knowledge alone was insufficient to improve team performance and highlighted communication and team behaviour as key indicators. They concluded that simulation was an effective technique to teach communication and teamwork skills through the use of crisis resource management (CRM) training to improve compliance with the introduction of new clinical treatment bundles. However Kim et al (2009) identified that there was no gold standard for evaluating team CRM performance and therefore compared the use of two tools to evaluate team performance, a global rating scale and a checklist rating instrument, in the resuscitation of critically ill patients during simulated emergencies. Again they found that simulation could play a key role in the evaluation of CRM performance and that the tools demonstrated both construct validity and moderate inter-rater reliability they could be used to evaluate performance. However, they recommended that further studies should be undertaken. Using another simulation modality, standardised patients, Schmitz et al (2008) developed an Objective Structured Clinical Examination (OSCE) that aimed at assessing the ability of physicians to discuss end-of-life care with family members of intensive care unit patients. They found that the OSCE, which is a form of assessment in a simulation context (Alinier, 2003), was reliable and had a high content validity and therefore felt that this would serve as a useful formative evaluation tool (Schmitz et al., 2008). Again they recommended that further research was needed into this area. In line with the latter Buykx et al. (2011) describe an evidence-based educational model, FIRST2ACT, that focuses on the early recognition of deterioration in patents. As recommended in a clinical guideline of the National Institute for Health and Clinical Excellence (NICE, 2007) all staff caring for patients in acute hospital settings should have the education and training to ensure that they have the competencies to monitor, measure, interpret and respond promptly and appropriately to a deterioration in a patient's condition. Evaluations of the FIRST2ACT model indicate a substantial increase in the knowledge, confidence, and competence of participants related to the assessment and management of patient deterioration, and the authors (Buykx et al., 2011) recommend that the model should be considered for both undergraduate and post-registration education programs. All of the studies discussed demonstrate both innovative approaches to learning and teaching and a growing evidence base for the use of simulation in the Critical Care context.

In relation to equity of access and value for money Calhoun et al. (2011) demonstrated the feasibility of implementing an in-situ simulation programme within a paediatric critical care unit that encouraged growth of the programme as it was well received by participants, and allows substantial cost savings over investing in a physical resource such as a clinical simulation centre.

\section{Conclusions}

As recommended in some of these documents, it is not about investing more in educational resources and technology, but making better use of them by adopting sound educational principles, collaborating with others, and ensuring a quality control process. This, of course, relies on having the right people facilitating the learning experiences and making sure training is made compulsory across the board to ensure standardisation of practice and monitor levels of competence in various domains (cognitive, technical, and behavioural). Simulation, in all its disguises, offers a key medium for clinicians to improve and develop their skills, knowledge, and attitude, but this can only be achieved if it is supported locally 
within an institution and a department. The critical care setting is an environment that is rapidly evolving in many aspects, and where patient care needs to be delivered in a safe and timely manner at all times. A number of initiatives relating to critical care and using simulation as a training intervention have started to provide encouraging outcomes in terms of improved patient care but more work is still required. The guidelines and standards which have been recently developed and published by specialist societies or healthcare authorities are based on current best educational practice. These should be carefully considered to ensure the effectiveness of training intervention in order to improve patient care and clinical outcomes.

\section{What is known about this topic:}

- Simulation in its various forms is now used in most healthcare professions and specialties.

- Simulation methodologies can be used during initial training as well as during continuing medical education or continuing professional development.

- Simulation serves as a bridge between the acquisition and application of clinical skills, knowledge, and attributes.

- There is increasing recognition that simulation is a technique more significantly affected by the process than by the tool used.

\section{What this paper adds:}

- Guidelines and recommendations based on current best simulation education practice are now developed and made available by international learned societies and other official bodies.

- High-level initiatives promoting the use of simulation in healthcare education are emerging around the world.

- Studies on the educational effectiveness of simulation-based interventions demonstrate enhanced acquisition of skills and knowledge on the part of healthcare providers and improved patient outcome.

\section{References:}

ABE, Y., KAWAHARA, C., YAMASHINA, A. \& TSUBOI, R. (2013) Repeated scenario simulation to improve competency in critical care: a new approach for nursing education. American Journal of Critical Care, 22, 33-40.

ABRAHAMSON, S., DENSON, J. S. \& WOLF, R. M. (1969) Effectiveness of a simulator in training anesthesiology residents. Journal of Medical Education, 44, 515-9.

AIMS - ADVANCEMENT IN MEDICAL SIMULATION (2009) The Enhancing SIMULATION Act. Available at: www.medsim.org/news detail.php?news id=118 (accessed 13 December 2012). 
ALINIER, G. (2003) Nursing students' and lecturers' perspectives of objective structured clinical examination incorporating simulation. Nurse Education Today, 23, 419-26.

ALINIER, G. (2007) A typology of educationally focused medical simulation tools. Medical Teacher, 29, e243-50.

AUSSETT - AUSTRALIAN SIMULATION EDUCATOR AND TECHNICIAN/COORDINATOR TRAINING PROGRAM (2012) Welcome to the AusSETT Program. Available at: http://www.aussett.edu.au/ (accessed 13 December 2012).

BURDEN, A. R., TORJMAN, M. C., DY, G. E., JAFFE, J. D., LITTMAN, J. J., NAWAR, F., RAJARAM, S. S., SCHORR, C., STAMAN, G. W. \& REBOLI, A. C. (2012) Prevention of central venous catheterrelated bloodstream infections: is it time to add simulation training to the prevention bundle? Journal of Clinical Anesthesiology, 24, 555-60.

BUYKX, P., KINSMAN, L., COOPER, S., MCCONNELL-HENRY, T., CANT, R., ENDACOTT, R. \& SCHOLES, J. (2011) FIRST2ACT: Educating nurses to identify patient deterioration - A theory-based model for best practice simulation education. Nurse Education Today, 31, 687-693.

CALHOUN, A. W., BOONE, M. C., PETERSON, E. B., BOLAND, K. A. \& MONTGOMERY, V. L. (2011) Integrated in-situ simulation using redirected faculty educational time to minimize costs: a feasibility study. Simulation in Healthcare, 6, 337-44.

CARNEY, A. (2007) A year as a "simulation fellow". BMJ Career Focus, 334, 97.

CLAPPER, T. (2012) Development of a hybrid simulation course to reduce central line infections. Journal of Continuing Education in Nursing, 43, 218-24.

COHEN, E. R., FEINGLASS, J., BARSUK, J. H., BARNARD, C., O'DONNELL, A., MCGAGHIE, W. C. \& WAYNE, D. B. (2010) Cost savings from reduced catheter-related bloodstream infection after simulationbased education for residents in a medical intensive care unit. Simulation in Healthcare, 5, 98102.

DEPARTMENT OF HEALTH (2010) From equity to excellence: Liberating the NHS, London, HMSO.

DEPARTMENT OF HEALTH (2011) A framework for technology enhanced learning, London, HMSO.

DOYLE, D. J. (2002) Simulation in Medical Education: Focus on Anesthesiology. Medical Education Online, 7, 1-15.

ERICSSON, K. A. (2004) Deliberate practice and the acquisition and maintenance of expert performance in medicine and related domains. Academic Medicine, 79, S70-81.

ERICSSON, K. A. (2008) Deliberate practice and acquisition of expert performance: a general overview. Academic Emergency Medicine, 15, 988-94.

ERICSSON, K. A., KRAMPE, R. T. \& TESCH-RÖMER, C. (1993) The Role of Deliberate Practice in the Acquisition of Expert Performance. Psychological Review, 100, 363-406.

FORD, D. G., SEYBERT, A. L., SMITHBURGER, P. L., KOBULINSKY, L. R., SAMOSKY, J. T. \& KANE-GILL, S. L. (2010) Impact of simulation-based learning on medication error rates in critically ill patients. Intensive Care Medicine, 36, 1526-31.

GELBART, N. R. (1998) The King's Midwife: A History and Mystery of Madame du Coudray, Bekerley, CA, University of California Press.

GRANRY, J. C. \& MOLL, M. C. (2012) État de l'art (national et international) en matière de pratiques de simulation dans le domaine de la santé. France, Haute Autorité de Santé.

HAS - HAUTE AUTORITÉ DE SANTÉ (2012) Guide de bonnes pratiques en matière de simulation en santé. Available at: http://www.has-sante.fr/portail/icms/c 1355008/guide-bonnes-pratiquessimulation-sante-guide (accessed 5 January 2013).

HEA \& ASPIH (2012) HEA ASPiH Simulation Development Officers (SDO's) - Update and FAQ's (4th June 2012). York, Higher Education Academy - Association for Simulated Practice in Healthcare.

HUANG, Y. M., PLIEGO, J. F., HENRICHS, B., BOWYER, M. W., SIDDALL, V. J., MCGAGHIE, W. C. \& RAEMER, D. (2008) 2007 Simulation Education Summit. Simulation in Healthcare, 3, 186-191. 
HWA - HEALTH WORKFORCE AUSTRALIA (2009) Simulated Learning Environments program updates. Available at: www.hwa.gov.au/work-programs/clinical-training-reform/simulated-learningenvironments-sles/updates (accessed 13 October 2012).

ICS - INTENSIVE CARE SOCIETY (2012) ICS \& FICM Simulation. Available at: http://www.ics.ac.uk/education/ics ficm simulation/ics ficm simulation (accessed 15 February 2013).

INACSL - INTERNATIONAL NURSING ASSOCIATION FOR CLINICAL SIMULATION AND LEARNING (2011) Standards of Best Practice: Simulation. Clinical Simulation in Nursing, 7, S1-S19.

ISSENBERG, S., B. (2006a) Michael S. Gordon, MD, PhD and the University of Miami Center for Research in Medical Education. Simulation in Healthcare, 1, 233-237.

ISSENBERG, S. B. (2006b) The scope of simulation-based healthcare education. Simulation in Healthcare, 1, 203-208.

JANSSON, M., KÄÄRIÄINEN, M. \& KYNGÄS, H. (in press) Effectiveness of Simulation-Based Education in Critical Care Nurses' Continuing Education: A Systematic Review. Clinical Simulation in Nursing, 1-6.

KIM, J., NEILIPOVITZ, D., CARDINAL, P. \& CHIU, M. (2009) A comparison of global rating scale and checklist scores in the validation of an evaluation tool to assess performance in the resuscitation of critically ill patients during simulated emergencies (abbreviated as "CRM simulator study IB"). Simulation in Healthcare, 4, 6-16.

KNEEBONE, R., ARORA, S., KING, D., BELLO, F., SEVDALIS, N., KASSAB, E., AGGARWAL, R., DARZI, A. \& NESTEL, D. (2010) Distributed simulation-accessible immersive training. Medical Teacher, 32, 6570.

KNEEBONE, R. L., SCOTT, W., DARZI, A. \& HORROCKS, M. (2004) Simulation and clinical practice: strengthening the relationship. Medical Education, 38, 1095-102.

LAM, G., AYAS, N. T., GRIESDALE, D. E. \& PEETS, A. D. (2010) Medical simulation in respiratory and critical care medicine. Lung, 188, 445-57.

LAMBTON, J. \& PRION, S. (2009) The value of simulation in the development of observational skills for clinical microsystems. Clinical Simulation in Nursing, 5, e137-e143.

LEIGH, G. \& HURST, H. (2008) We Have a High-Fidelity Simulator, Now What? Making the Most of Simulators. International Journal of Nursing Education Scholarship, 5, 1-9.

LIND, B. (1961) Teaching mouth-to-mouth resuscitation in primary schools. ACTA Anaesthesiologica Scandinavica Supplementum, Suppl 9, 63-81.

MAH, J. W., BINGHAM, K., DOBKIN, E. D., MALCHIODI, L., RUSSELL, A., DONAHUE, S., STAFF, I., IVY, M. E. \& KIRTON, O. C. (2009) Mannequin simulation identifies common surgical intensive care unit teamwork errors long after introduction of sepsis guidelines. Simulation in Healthcare, 4, 193-9.

MCGAGHIE, W. C., ISSENBERG, S. B., PETRUSA, E. R. \& SCALESE, R. J. (2010) A critical review of simulation-based medical education research: 2003-2009. Medical Education, 44, 50-63.

MEDLEY, C. F. \& HORNE, C. (2005) Using Simulation Technology for Undergraduate Nursing Education. Journal of Nursing Education, 44, 31-34.

NICE (2007) NICE Clinical Guideline 50: Acutely ill patients in hospital - Recognition of and response to acute illness in adults in hospitals, London, National Institute for Health and Clinical Excellence.

NURSING AND MIDWIFERY COUNCIL (2007) Supporting Direct Care through simulated Practice in the pre-registration programme. NMC Circular 36/2007.

ROSEN, K. R. (2008) The history of medical simulation. Journal of Critical Care, 23, 157-166.

SCHMITZ, C. C., CHIPMAN, J. G., LUXENBERG, M. G. \& BEILMAN, G. J. (2008) Professionalism and communication in the intensive care unit: reliability and validity of a simulated family conference. Simulation in Healthcare, 3, 224-38. 
SMITH, C. C., HUANG, G. C., NEWMAN, L. R., CLARDY, P. F., FELLER-KOPMAN, D., CHO, M., ENNACHERIL, T. \& SCHWARTZSTEIN, R. M. (2010) Simulation training and its effect on long-term resident performance in central venous catheterization. Simulation in Healthcare, 5, 146-51.

SSH - SOCIETY FOR SIMULATION IN HEALTHCARE (2012) SSH Accreditation of Healthcare Simulation Programs. Available at: http://ssih.org/accreditation-of-healthcare-simulation-programs (accessed 5 January 2013).

SSH - SOCIETY FOR SIMULATION IN HEALTHCARE (2013) About Certified Healthcare Simulation Educator - Transform Simulation Education, Get Certified! , Available at: http://ssih.org/certification/aboutCHSE (accessed 15 February 2013).

WAXMAN, K. T., NICHOLS, A. A., O'LEARY-KELLEY, C. \& MILLER, M. (2011) The Evolution of a Statewide Network: The Bay Area Simulation Collaborative. Simulation in Healthcare, 6, 345-351. 